\title{
Long-term adherence to inhaled corticosteroids and asthma control in adult-onset asthma
}

\author{
lida Vähätalo (101,2, Hannu Kankaanranta ${ }^{1,2,3}$, Leena E. Tuomisto (10 ${ }^{1,2}$, \\ Onni Niemelä ${ }^{2,4}$, Lauri Lehtimäki $i^{2,5}$ and Pinja Ilmarinen (i) ${ }^{1,2}$
}

Affiliations: ${ }^{1}$ Dept of Respiratory Medicine, Seinäjoki Central Hospital, Seinäjoki, Finland. ${ }^{2}$ Tampere University Respiratory Research Group, Faculty of Medicine and Health Technology, Tampere University, Tampere, Finland. ${ }^{3}$ Krefting Research Centre, Institute of Medicine, Dept of Internal Medicine and Clinical Nutrition, University of Gothenburg, Gothenburg, Sweden. ${ }^{4}$ Dept of Laboratory Medicine, Seinäjoki Central Hospital, Seinäjoki, Finland. ${ }^{5}$ Allergy Centre, Tampere University Hospital, Tampere, Finland.

Correspondence: lida Vähätalo, Dept of Respiratory Medicine, Seinäjoki Central Hospital, FIN-60220 Seinäjoki, Finland. E-mail: iida.vahatalodepshp.fi

\section{ABSTRACT}

Background: In short-term studies, poor adherence to inhaled corticosteroids (ICS) has been associated with worse asthma control, but the association of long-term adherence and disease control remains unclear.

Objective: To assess the relationship between 12-year adherence to ICS and asthma control in patients with adult-onset asthma.

Methods: As part of the Seinäjoki Adult Asthma Study, 181 patients with clinically confirmed new-onset adult asthma and regular ICS medication were followed-up for 12 years. Adherence (\%) to ICS was assessed individually $((\mu \mathrm{g}$ dispensed/ $\mu \mathrm{g}$ prescribed $) \times 100)$ during the follow-up. Asthma control was evaluated after 12 years of treatment according to the Global Initiative for Asthma 2010 guideline.

Results: Asthma was controlled in 31\% and not controlled (partly controlled or uncontrolled) in $69 \%$ of the patients. Patients with not-controlled asthma were more often male, older, nonatopic and used higher doses of ICS than those with controlled disease. The mean \pm SD 12 -year adherence to ICS was $63 \pm 38 \%$ in patients with controlled asthma and $76 \pm 40 \%$ in patients with not-controlled disease $(\mathrm{p}=0.042)$. Among patients with not-controlled asthma, those with lower 12 -year adherence $(<80 \%)$ had more rapid decline in forced expiratory volume in $1 \mathrm{~s}\left(-47 \mathrm{~mL} \cdot \mathrm{year}^{-1}\right)$ compared to patients with better adherence $(\geqslant 80 \%)$ $\left(-40 \mathrm{~mL} \cdot \mathrm{year}^{-1}\right)(\mathrm{p}=0.024)$. In contrast, this relationship was not seen in patients with controlled asthma. Conclusions: In adult-onset asthma, patients with not-controlled disease showed better 12-year adherence to ICS treatment than those with controlled asthma. In not-controlled disease, adherence $<80 \%$ was associated with more rapid lung function decline, underscoring the importance of early recognition of such patients in routine clinical practice.

@ERSpublications

Patients with not-controlled asthma and poor adherence show increased FEV $_{1}$ decline. Special emphasis should be placed on ICS adherence in subjects who do not have controlled asthma, as they seem to be at higher risk of developing fixed airway obstruction. https://bit.ly/2LOXL4f

Cite this article as: Vähätalo I, Kankaanranta $\mathrm{H}$, Tuomisto LE, et al. Long-term adherence to inhaled corticosteroids and asthma control in adult-onset asthma. ERJ Open Res 2021; 7: 00715-2020 [https://doi.org/10.1183/23120541.00715-2020].

This article has supplementary material available from openres.ersjournals.com

This study is registered at www.clinicaltrials.gov with identifier number NCT02733016.

Received: 1 Oct 2020 | Accepted after revision: 12 Dec 2020

Copyright $\odot$ ERS 2021. This article is open access and distributed under the terms of the Creative Commons Attribution Licence 4.0. 


\section{Introduction}

Successful asthma treatment plays a pivotal role in preventing exacerbations, enhancing patients' quality of life and decreasing healthcare costs [1]. Asthma often remains poorly controlled despite effective pharmacological treatment strategies [2-4] and current guidelines emphasise the importance of finding out the reason behind not-controlled asthma in each patient [5]. Age of asthma onset has been shown to differentiate the phenotypes of asthma [6,7], but very little information exists on the disease control characteristics of the late-onset asthma phenotype [3].

To gain optimal benefits from pharmacotherapy, patients should be adherent to treatment, which has been shown to be often suboptimal $[1,8]$. Only two studies so far have evaluated long-term adherence to inhaled corticosteroids (ICS): the Childhood Asthma Management Program (CAMP) (4-year follow-up) [9] and the Seinäjoki Adult Asthma Study (SAAS) (12-year follow-up) [8]. In these studies, mean adherence to ICS was 52\% and 69\%, respectively. Previous studies assessing asthma control and adherence have been either cross-sectional or with short follow-up [10-18]. In addition, the evaluation of adherence and asthma control has mostly been questionnaire-based and information concerning diagnostic criteria, duration and age of onset of asthma are often missing, potentially influencing the results $[4,13,15]$. Poor asthma control has been associated with higher risk of exacerbations, lower quality of life and increased healthcare use $[2,4,10,19]$. Previous studies have suggested that suboptimal adherence to pharmacological therapy impairs asthma control $[4,10-13,20]$. In contrast, a recent study identified that patients with uncontrolled asthma were more adherent to ICS treatment [21]. However, the adherence was determined from prescriptions issued, reflecting the physician's prescription manners, not the adherence of the patient. It should be noted that in previous studies medication possession ratio (MPR) and proportion of days covered (PDC) formulas have been used regularly for estimating adherence $[1,21]$. Unfortunately, the data used in these formulas usually lack detail, such as did patients have continuous prescription for ICS and how were dose ranges and single maintenance and reliever therapy regarded, all being relevant issues in the treatment of asthma.

Inadequate use of preventer medication is suggested to be related to decline in lung function, but there are no data on the association between long-term adherence and lung function decline stratified by asthma control. An Australian study [22] found accelerated lung function in patients not taking adequate preventer therapy. Furthermore, in previous short-term (1-year) follow-up study conducted in the United Kingdom [23], patients with difficult-to-control asthma and suboptimal ICS adherence had reduced forced expiratory volume in $1 \mathrm{~s}\left(\mathrm{FEV}_{1}\right)$. In our recent study, poorer 12-year adherence was related to lung function decline in the long-term, but patients with good adherence used more add-on drugs, oral corticosteroid courses, had more hospital days and used more healthcare services, i.e. had features suggesting not-controlled asthma [8]. Thus, we hypothesised that not-controlled asthma is not a direct consequence of poor adherence and that lung function decline does not depend on poor adherence only, but may be affected by asthma control. Hence this study aimed to assess the relationship between 12-year adherence to ICS and asthma control in patients with adult-onset asthma, especially concentrating on whether the effect of poor adherence on lung function decline is affected by asthma control. In this study, we used full-coverage dispensing data and information on prescribed ICS, offering the possibility to assess real-life adherence based on dispensed and prescribed amounts of ICS [8, 24].

\section{Methods}

\section{Study design and patients}

The current study is part of SAAS, which is a prospective 12-year follow-up study of patients with diagnosis of new-onset adult asthma. All new adult (age $\geqslant 15$ years) patients in Seinäjoki Central Hospital were included during the period 1999-2002. Diagnostic criteria, inclusion and exclusion criteria have been reported previously [25] (supplementary eTable 1). Patients with comorbidities or smoking history were not excluded. Study participants gave written informed consent to the study protocol approved by the ethics committee of Tampere University Hospital (Tampere, Finland).

The study was divided into two parts: baseline visit and 12-year follow-up visit (figure 1). At the baseline visit, data were collected on symptoms, lung function and demographics, as described previously [25]. Furthermore, regular ICS medication was prescribed and each patient received asthma education, advice on correct inhaler use and self-management instructions according to the Finnish asthma programme [26]. From the original cohort of 257 patients, 203 (79\%) returned for the 12-year follow-up visit in which asthma control, medication and lung function were evaluated (supplementary material). All asthma-related visits and medication information were collected for the whole 12-year follow-up period from medical records [24]. To ensure that the study population included only patients with regular ICS medication, we excluded patients for whom ICS was prescribed only periodically (often Global Initiative for Asthma (GINA) step 1 and ICS use during pollen season) at any point of the follow-up (figure 1). 



FIGURE 1 Flow-chart of the study. ICS: inhaled corticosteroids; GINA: Global Initiative for Asthma; ACT: Asthma Control Test; AQ20: Airway Questionnaire 20 .

Asthma control and lung function

Asthma control was defined according to GINA 2010 [27] and "not-controlled" included both partially and uncontrolled asthma (supplementary material). Lung function measurement points were 1) baseline (diagnosis), 2$)$ the maximum lung function $\left(\max _{0-2.5}\right)$ during the first 2.5 years after diagnosis (after start of therapy) and 3) 12-year follow-up visit (supplementary material). Decline in lung function during the 12-year follow-up period was defined as change in pre-bronchodilator $\mathrm{FEV}_{1}$ from $\max _{0-2.5}$ to the 12 -year time point.

\section{Assessment of adherence}

The prescribed ICS dose in each patient for the 12-year period was calculated based on medication records, as described previously [24]. Briefly, we converted all prescribed ICS doses (ICS in both single and combination inhalers) to beclomethasone dipropionate equivalents, and based on that information, calculated annual prescribed ICS medication for each patient. The dispensed ICS doses were obtained from the Finnish Social Insurance Institution which records all medication purchased from any Finnish pharmacy. All drug and dose changes were taken into account individually. In the case of ranged doses prescribed (e.g. one or two puffs twice daily), we interpreted that patients were adherent when the minimum ICS doses were dispensed. Adherence to ICS was determined as described recently [8], consisting of initiation, implementation and persistence (supplementary material). The 12-year adherence was calculated by comparing cumulative dispensed doses of ICS $(\mu \mathrm{g})$ to cumulative prescribed doses of ICS $(\mu \mathrm{g})$ and annual adherence by comparing yearly dispensed doses of ICS ( $\mu \mathrm{g})$ to yearly prescribed doses of ICS $(\mu \mathrm{g})$. This adherence calculation combines elements from both MPR and PCD formulas (supplementary material) $[8,28]$ and we estimated the time-variance of the adherence according to a recent publication [29].

\section{Statistical analyses}

The results are shown as mean \pm SD or median (interquartile range), but annual adherence is represented as mean \pm SEM for clarity. Comparison of groups with $\geqslant 80 \%$ or $<80 \%$ adherence to ICS were analysed by using independent samples t-test and Mann-Whitney U-test for normally and non-normally distributed continuous variables, respectively, and Pearson's Chi-squared or Fisher's exact test for categorical variables. To analyse differences in annual adherence over the 12-year period between controlled and not-controlled patients, annual adherence was plotted against time for individual patients, and mean area under curve values were compared using an independent samples t-test. A multivariable binary logistic regression analysis was performed to analyse factors associated with not-controlled asthma. A multiple linear regression analysis was performed to analyse factors associated with $\mathrm{FEV}_{1}$ decline, as described previously [30]. The correlation matrix was analysed and covariates not strongly correlated $(\mathrm{r}<0.7)$ (age, sex, body mass index (BMI) at follow-up, exhaled nitric oxide fraction $\left(F_{\text {eNO }}\right)>20 \mathrm{ppb}, \geqslant 10$ pack-years at follow-up, change $(\Delta)$ in $\mathrm{FEV}_{1}$ (baseline- $\max _{0-2.5}$ ) and average 12 -year adherence $(<80 \%)$ to ICS) were included in the analysis and outliers were removed to ensure homoscedasticity (supplementary material). A p-value $<0.05$ was regarded as statistically significant. Statistical analyses were performed using SPSS statistics software (version 24; IBM, Armonk, NY, USA) and GraphPad Prism (version 7.03; GraphPad, La Jolla, CA, USA). 


\section{Results}

\section{Patient characteristics}

The majority of the study patients were female (60\%), the average age was $59 \pm 13$ years at the follow-up visit and half of the patients were current or ex-smokers (supplementary eTable 2). At the follow-up visit patients had higher BMI, better lung function, lower blood eosinophil counts and fewer symptoms (Asthma Questionnaire 20) compared to the baseline visit (supplementary eTable 2).

\section{Asthma control}

At the 12-year follow-up visit, asthma control was evaluated and the patients were divided into two groups: controlled $(n=56)$ and not controlled $(n=125)$. Group characteristics are shown in table 1. Patients with not-controlled asthma were more often male, older and were prescribed higher doses of ICS than

\begin{tabular}{|c|c|c|c|}
\hline & Controlled & Not-controlled & p-value \\
\hline Patients & 56 & 125 & \\
\hline Age years & $56 \pm 14.6$ & $61 \pm 12.4$ & $0.011^{++}$ \\
\hline Female & $41(73.2)$ & $67(53.6)$ & $0.014^{\S \S}$ \\
\hline BMI $\mathrm{kg} \cdot \mathrm{m}^{-2}$ & $27.6 \pm 3.8$ & $29.1 \pm 6.0$ & $0.079^{++}$ \\
\hline Smokers (including ex-smokers) & $18(32.1)$ & $73(58.4)$ & $0.001^{\S \S}$ \\
\hline Smoking history pack-years & $7(2-12)$ & $20(10-32)$ & $<0.001^{f f}$ \\
\hline$\geqslant 10$ pack-years and post-BD $\mathrm{FEV}_{1} / \mathrm{FVC}<0.7^{\uparrow}$ & $4(7.1)$ & $29(23.4)$ & $0.011^{\S \S}$ \\
\hline Pre-BD FEV $1 \%$ pred & $92(86-99)$ & $82(70-93)$ & $<0.001^{f f}$ \\
\hline Pre-BD FEV 1 /FVC & $0.75(0.70-0.79)$ & $0.73(0.64-0.78)$ & $0.016^{f f}$ \\
\hline Post-BD FEV $\%$ pred & $96(90-101)$ & $84(75-96)$ & $<0.001^{f f}$ \\
\hline Post-BD FEV $/$ FVC & $0.77(0.73-0.83)$ & $0.73(0.65-0.79)$ & $0.002^{f f}$ \\
\hline Blood eosinophils $\times 10^{9} \cdot \mathrm{L}^{-1}$ & $0.17(0.12-0.28)$ & $0.18(0.09-0.27)$ & $0.353^{f f}$ \\
\hline Total $\lg E \mathrm{kU} \cdot \mathrm{L}^{-1}$ & $51(28-161)$ & $71(24-172)$ & $0.617^{f f}$ \\
\hline$F_{\mathrm{eNO}} \mathrm{ppb}$ & $12(6-19)$ & $10(5-18)$ & $0.392^{f f}$ \\
\hline Blood neutrophils $\times 10^{9} \cdot \mathrm{L}^{-1}$ & $3.7(3.0-4.6)$ & $3.9(2.9-4.9)$ & $0.522^{f f}$ \\
\hline Prescribed daily dose of ICS $\mu \mathrm{g}$ BDP & 751 (502-939) & $838(664-1023)$ & $0.014^{f f}$ \\
\hline Dispensed daily dose of ICS $\mu \mathrm{g}$ BDP & $411(246-625)$ & $602(354-838)$ & $0.002^{f f}$ \\
\hline Daily SABA ${ }^{+}$ & $2(3.6)^{\# \# \#}$ & $19(15.2)$ & $0.024^{\S \S}$ \\
\hline Daily LABA ${ }^{+}$ & $18(32.1)$ & $77(61.6)$ & $<0.001^{\S \S}$ \\
\hline $\begin{array}{l}\text { Self-reported use of oral corticosteroid courses for } \\
\text { asthma }\end{array}$ & $12(21.4)$ & $48(39.0)$ & $0.06^{\S \S}$ \\
\hline Dispensed oral corticosteroid for asthma per year $\mathrm{mg}^{f}$ & $44(0-127)$ & $92(0-240)$ & $0.013^{f f}$ \\
\hline Comorbidities & $1(0-2)$ & $1(0-3)$ & $0.057 f f$ \\
\hline Co-medications (nonrespiratory) & $1(0-4)$ & $2(0-4)$ & $0.124^{f f}$ \\
\hline AQ20 score & $2(0-4)$ & $6(3-9)$ & $<0.001^{f f}$ \\
\hline ACT score & $24(22-25)$ & $20(17-23)$ & $<0.001^{f f}$ \\
\hline Asthma-related visits to healthcare ${ }^{\S, \# \#}$ & $12(6-19)$ & $16(10-26)$ & $0.014^{f f}$ \\
\hline Atopy & $27(50.9)$ & $34(30.6)$ & $0.016^{\S \S}$ \\
\hline $\begin{array}{l}\geqslant 1 \text { hospital in-patient periods, asthma-related } \\
\text { (unplanned) }{ }^{\S}\end{array}$ & $1(1.8)$ & 15 (12.0) & $0.024^{\S \S}$ \\
\hline
\end{tabular}

Data are presented as $\mathrm{n}$, mean $\pm \mathrm{SD}, \mathrm{n}(\%)$ or median (interquartile range), unless otherwise stated. $\mathrm{BMI}$ : body mass index; $\mathrm{BD}$ : bronchodilator; $\mathrm{FEV}_{1}$ : forced expiratory volume in $1 \mathrm{~s}$; FVC: forced vital capacity; $\lg \mathrm{E}$ : immunoglobulin $E_{;} F_{\mathrm{eNO}}$ : exhaled nitric oxide fraction; ICS: inhaled corticosteroid; BDP: beclomethasone dipropionate equivalents; SABA: short-acting $\beta_{2}$-agonist; LABA: long-acting $\beta_{2}$-agonist; AQ20: Airways Questionnaire 20; ACT: Asthma Control Test. "\#: the results of lung function and inflammatory parameters have been published previously in patients with controlled, partially controlled and uncontrolled asthma [3]; ๆ: baseline $\geqslant 10$ pack-years and post-BD FEV $1 / F V C$ ratio $<0.7$ in patients with controlled asthma $(n=2,3.6 \%)$ and patients with not-controlled asthma $(n=13,10.7 \%)(p=0.150) ;{ }^{+}$: self-reported daily use; ${ }^{\text {§: }}$ : examined during the whole 12-year follow-up period; ${ }^{f}$ : values obtained from the Finnish Social Insurance Institution and were divided by the years of follow-up; ${ }^{\# \#}$ : all respiratory-related scheduled and unscheduled contacts with healthcare due to asthma; กा: defined as $\geqslant 1$ positive response ( $\geqslant 3 \mathrm{~mm})$ in skin prick test towards common aeroallergens [31]; ${ }^{++}$: independent samples t-test; ${ }^{\S \S}$ : Fisher's exact test; ${ }^{f f}$ : independent samples Mann-Whitney U-test; ${ }^{\# \# \#}$ : these two patients were not dispensed SABA in the year when asthma control was determined and therefore they were considered to belong to the group of controlled patients. However, they self-reported daily use of SABA and more SABA was dispensed in preceding years of the follow-up. 

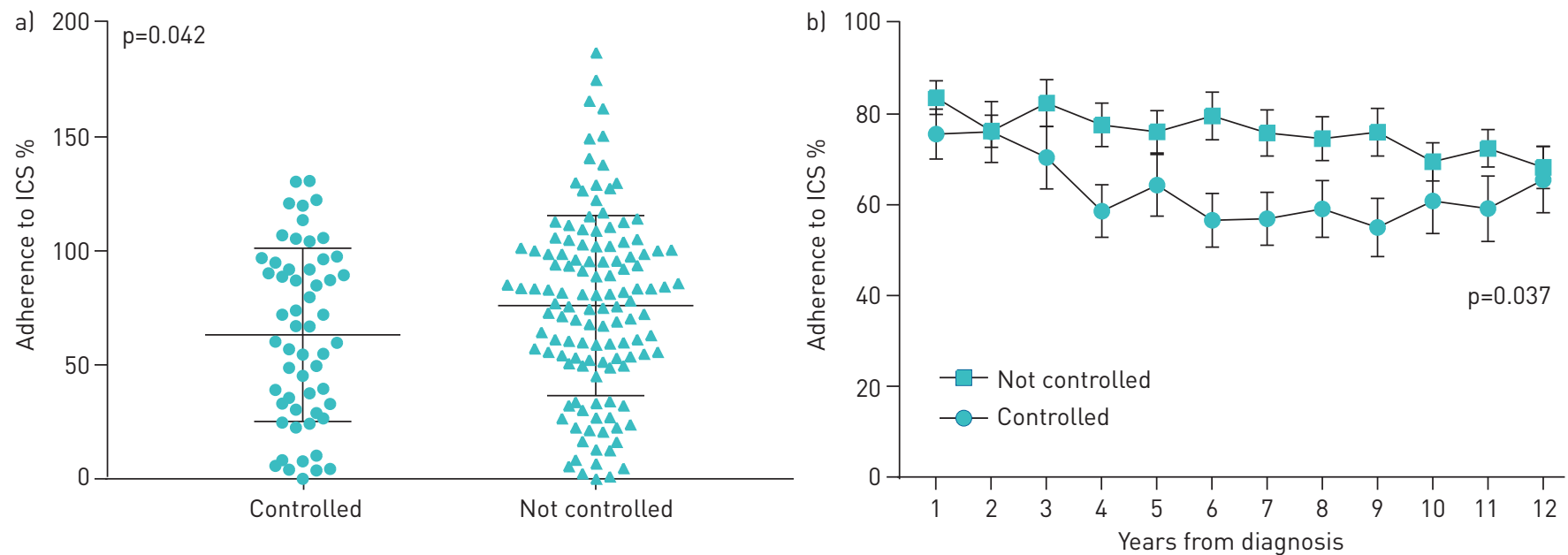

FIGURE 2 Long-term adherence to inhaled corticosteroids (ICS) in patients with controlled and not-controlled asthma. a) The average 12-year adherence to ICS in study subgroups (mean \pm SD). Adherence $>100 \%$ means that patients were dispensed more than a regular individually prescribed minimum dose of ICS. b) The average annual adherence (mean \pm SEM) in patients with controlled and not-controlled asthma during the 12-year follow-up period. p-value represents difference in annual ICS adherence between not-controlled and controlled patients as defined by area under the curve method and independent-samples t-test. Significant difference was also seen when patients with COPD were excluded from the analyses (a) $p=0.021$ and b) $p=0.019$ ).

patients with controlled asthma. As reported previously, lung function was better and smoking was less common in patients with controlled asthma versus not-controlled asthma [3]. Patients with not-controlled asthma used more daily add-on drugs, had more days in hospital and were dispensed higher doses of oral corticosteroids (table 1). In addition, patients with not-controlled asthma were less often atopic and had a higher number of asthma-related contacts with healthcare. No difference was found in inflammatory parameters.

\section{Adherence and asthma control}

The mean \pm SD 12 -year adherence to ICS was $63 \pm 38 \%$ in patients with controlled asthma and $76 \pm 40 \%$ in patients with not-controlled disease $(\mathrm{p}=0.042)$ (figure $2 \mathrm{a}$ ). Patients with not-controlled asthma had significantly higher adherence $(\mathrm{p}=0.037)$ compared to patients with controlled asthma in the whole 12-year study period (figure 2b). Furthermore, $34 \%$ of the study patients had not-controlled asthma despite having $\geqslant 80 \%$ adherence to ICS treatment during 12-year follow-up (table 2). The association between $\geqslant 80 \%$ adherence and not-controlled asthma remained in binary logistic regression analysis adjusting for age $\geqslant 60$ years, BMI $\geqslant 30 \mathrm{~kg} \cdot \mathrm{m}^{-2}$, sex, COPD and rhinitis. When evaluating long-term ICS use, it was found that $76.8 \%$ of the patients with not-controlled asthma and $60.7 \%$ of the patients with controlled asthma were $>50 \%$ adherent to their ICS treatment each year during the 12-year follow-up $(\mathrm{p}=0.032)$.

\section{Not-controlled asthma}

A large variation in the ICS adherence was found in the not-controlled asthma group. Therefore, we considered that there may be two different groups of patients with suboptimal asthma control: 1) those having not-controlled asthma due to low adherence to ICS; and 2) those having not-controlled asthma despite good adherence to ICS. To see whether clinical differences exist between these groups, we evaluated asthma-related parameters in patients having not-controlled asthma and $\geqslant 80 \%$ or $<80 \% 12$-year adherence (table 2 and supplementary eTable 3 ). The patients having not-controlled asthma and $\geqslant 80 \%$ adherence had a higher number of asthma-related contacts with healthcare, higher blood neutrophil count and used more often long-acting $\beta_{2}$-agonists (LABA) or leukotriene receptor antagonists (table 2).

\section{Controlled asthma}

Assessment of patients with good asthma control revealed that patients with $\geqslant 80 \%$ adherence had lower $\mathrm{BMI}$, higher total immunoglobulin $\mathrm{E}$ and peripheral blood neutrophil counts and lower $\mathrm{FEV}_{1}$ reversibility (mL) than patients with $<80 \%$ adherence and controlled asthma (table 3 and supplementary eTable 4 ). In addition, patients with controlled asthma and $\geqslant 80 \%$ adherence reported using oral corticosteroids more often and had tendency to increased asthma-related visits to healthcare compared to $<80 \%$ adherent patients. 


\begin{tabular}{|c|c|c|c|}
\hline & $\begin{array}{l}\text { Good adherence } \\
(1 \geqslant 80 \%)\end{array}$ & $\begin{array}{l}\text { Poor adherence } \\
\qquad<80 \%]\end{array}$ & p-value \\
\hline Patients & 61 & 64 & \\
\hline Age years & $62 \pm 12$ & $60 \pm 13$ & $0.242^{f}$ \\
\hline Female & $36(59.0)$ & $31(48.4)$ & $0.283^{\# \#}$ \\
\hline $\mathrm{BMI} \mathrm{kg} \cdot \mathrm{m}^{-2}$ & $28.4(24.6-32.5)$ & $28.5(24.5-32.3)$ & $0.286^{\text {กาก }}$ \\
\hline Smokers (including ex-smokers) & $35(57.4)$ & $38(59.4)$ & $0.857^{\# \#}$ \\
\hline Smoking history pack-years & $19(9-34)$ & $20(12-30)$ & 0.977 กิก \\
\hline Pre-BD FEV $1 \%$ pred & 84 (71-99) & $80(70-90)$ & 0.200 ๆาก \\
\hline Pre-BD FEV 1 /FVC & $0.73(0.65-0.78)$ & $0.72(0.63-0.78)$ & 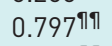 \\
\hline Post-BD FEV ${ }_{1} \%$ pred & $84(75-99)$ & $84(75-92)$ & $0.386^{\text {กิก }}$ \\
\hline Post-BD FEV 1 /FVC & $0.73(0.66-0.79)$ & $0.73(0.65-0.80)$ & $0.888^{\text {กิก }}$ \\
\hline Blood eosinophils $\times 10^{9} \cdot \mathrm{L}^{-1}$ & $0.15(0.08-0.25)$ & $0.19(0.10-0.29)$ & 0.118 กาก \\
\hline Total IgE kU: $\mathrm{L}^{-1}$ & $61(23-138)$ & 79 (29-197) & 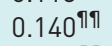 \\
\hline Blood neutrophils $\times 10^{9} \cdot \mathrm{L}^{-1}$ & $4.2(3.4-5.2)$ & $3.5(2.7-4.6)$ & $0.022^{\text {กา }}$ \\
\hline Prescribed daily dose of ICS $\mu \mathrm{g}$ BDP & $841(704-1062)$ & $834(642-995)$ & $0.412^{\text {กา }}$ \\
\hline Dispensed daily dose of ICS $\mu \mathrm{g}$ BDP & $831(728-1+)$ & $375(210-520)$ & $<0.001$ ๆา \\
\hline Daily SABA & $13(21.3)$ & $6(9.4)$ & $0.082^{\# \#}$ \\
\hline Daily LABA $\#$ & $46(75.4)$ & $31(48.4)$ & $0.003^{\# \#}$ \\
\hline Daily LTRA ${ }^{\#}$ & $16(26.2)$ & $6(9.5)$ & $0.019^{\# \#}$ \\
\hline $\begin{array}{l}\text { Self-reported use of oral corticosteroid } \\
\text { courses for asthma }\end{array}$ & $26(44.1)$ & $22(34.4)$ & $0.355^{\# \#}$ \\
\hline $\begin{array}{l}\text { Dispensed oral corticosteroid for asthma per } \\
\text { year } \mathrm{mg}^{+}\end{array}$ & $125(10-273)$ & 70 (0-193) & $0.176^{\text {กิก }}$ \\
\hline Co-medications (non-respiratory) & $2(1-5)$ & $2(0-4)$ & $0.116^{\text {กิก }}$ \\
\hline AQ20 score & $6(3.5-8)$ & $5.5(2-10)$ & $0.822^{\text {ๆๆ }}$ \\
\hline ACT score & $21(18-23)$ & $20(16-23)$ & 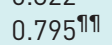 \\
\hline Allergy and/or rhinitis & $45(73.8)$ & $46(71.9)$ & $0.843^{\# \#}$ \\
\hline Asthma-related visits to healthcare ${ }^{\eta, \S}$ & $19(13-28)$ & $13(9-22)$ &  \\
\hline
\end{tabular}

Data are presented as $\mathrm{n}$, mean $\pm \mathrm{SD}, \mathrm{n}(\%)$ or median (interquartile range), unless otherwise stated. BMI: body mass index; $\mathrm{BD}$ : bronchodilator; $\mathrm{FEV}_{1}$ : forced expiratory volume in $1 \mathrm{~s}$; FVC: forced vital capacity; IgE:

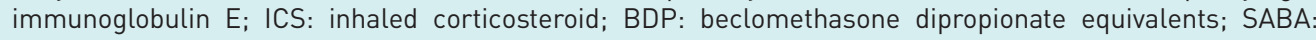
short-acting $\beta_{2}$-agonist; LABA: long-acting $\beta_{2}$-agonist; LTRA: leukotriene receptor antagonist; AQ20: Airways Questionnaire 20; ACT: Asthma Control Test. \#: self-reported daily use; ": examined during the whole 12-year follow-up period; ${ }^{+}$: dispensed doses of oral corticosteroids (mgl were obtained from the Finnish Social Insurance Institution and were divided by the years of follow-up; § : all respiratory-related scheduled and unscheduled contacts with healthcare due to asthma; ${ }^{f}$ : independent samples t-test; ${ }^{\# \#}$ : Fisher's exact test; "ๆๆ: independent samples Mann-Whitney U-test.

\section{Decline in lung function}

Next we evaluated the change in lung function in patients with controlled and not-controlled asthma and in groups of $\geqslant 80 \%$ and $<80 \% 12$-year adherence. The patients with not-controlled asthma and $<80 \%$ 12 -year adherence had more rapid decrease in lung function $\left(\mathrm{FEV}_{1}\right)$ compared to patients with $\geqslant 80 \%$ adherence $(\mathrm{p}=0.024)$ (table 4, figure 3). However, no difference was found in patients with controlled asthma between the adherence groups (table 4). We carried out multiple linear regression analysis to find out whether poor adherence predicts accelerated lung function decline in patients with not-controlled asthma when adjusted for age, BMI at follow-up, sex, $F_{\mathrm{eNO}}>20 \mathrm{ppb}, \geqslant 10$ pack-years and $\Delta \mathrm{FEV}_{1}$ (baseline- $\left.\max _{0-2.5}\right)$ (table 5). After adjustments, poorer adherence $(<80 \%)$ remained a significant predictor for $\mathrm{FEV}_{1}(\mathrm{~mL})$ decline.

\section{Discussion}

In this study we evaluated both annual and 12-year adherence to ICS from diagnosis to 12-year follow-up visit in patients with adult-onset asthma and different categories of asthma control. The mean adherence to ICS was better in patients with not-controlled than controlled asthma (76\% versus $63 \%$ ). Considering patients with not-controlled asthma, good 12 -year adherence $(\geqslant 80 \%)$ was associated with daily use of LABA and higher number of peripheral blood neutrophils and asthma-related contacts to healthcare. Importantly, in patients with not-controlled asthma, $<80 \%$ adherence predicted more rapid lung function decline in adjusted analyses. 
TABLE 3 Characteristics of patients with controlled asthma at 12 years after diagnosis according to their level of 12 -year adherence $(n=56)$

\begin{tabular}{|c|c|c|c|}
\hline & $\begin{array}{c}\text { Good adherence } \\
\quad(\geqslant 80 \%)\end{array}$ & $\begin{array}{c}\text { Poor adherence } \\
{[<80 \%]}\end{array}$ & p-value \\
\hline Patients & 21 & 35 & \\
\hline Age years & $58 \pm 11$ & $54 \pm 16$ & $0.266^{f}$ \\
\hline Female & $16(76.2)$ & 25 (71.4) & $0.764^{\# \#}$ \\
\hline $\mathrm{BMI} \mathrm{kg} \cdot \mathrm{m}^{-2}$ & $26.3(3.4)$ & $28.3(3.8)$ & $0.045^{f}$ \\
\hline Smokers (including ex-smokers) & $5(23.8)$ & $13(37.1)$ & $0.382^{\# \#}$ \\
\hline Smoking history pack-years & $10(3.7-14.8)$ & $5.3(1.3-9.3)$ & 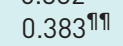 \\
\hline Pre-BD FEV $1 \%$ pred & $91(86-100)$ & $92(86-98)$ & $0.939^{\text {ติ }}$ \\
\hline Pre-BD FEV 1 /FVC & $0.74(0.68-0.80)$ & $0.75(0.71-0.79)$ &  \\
\hline Post-BD FEV $\%$ pred & $96(90-100)$ & $96(91-102)$ & 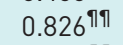 \\
\hline Post-BD FEV $1 /$ FVC & $0.75(0.71-0.82)$ & $0.78(0.73-0.83)$ & $0.285^{\text {ติ }}$ \\
\hline Blood eosinophils $\times 10^{9} \cdot \mathrm{L}^{-1}$ & $0.25(0.13-0.37)$ & $0.15(0.11-0.26)$ &  \\
\hline Total IgE kU: $\mathrm{L}^{-1}$ & $93(39-214)$ & $43(23-95)$ &  \\
\hline Blood neutrophils $\times 10^{9} \cdot \mathrm{L}^{-1}$ & $3.9(3.6-5.5)$ & $3.6(2.6-3.9)$ & 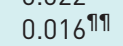 \\
\hline Prescribed daily dose of ICS $\mu \mathrm{g}$ BDP & $620(488-1017)$ & $800(541-925)$ & $0.565^{\text {ติ }}$ \\
\hline Dispensed daily dose of ICS $\mu \mathrm{g}$ BDP & $628(476-983)$ & $301(90-402)$ & $<0.001^{\text {ๆก }}$ \\
\hline Daily SABA ${ }^{\#}$ & $0(0)$ & $2(5.7)$ & $0.523^{\# \#}$ \\
\hline Daily LABA & $8(38.1)$ & $10(28.6)$ & $0.558^{\# \#}$ \\
\hline Daily LTRA ${ }^{\#}$ & $2(9.5)$ & 2 (5.7) & $0.626^{\# \#}$ \\
\hline $\begin{array}{l}\text { Self-reported use of oral corticosteroid } \\
\text { courses for asthmaף }\end{array}$ & $8(38.1)$ & $4(11.4)$ & $0.040^{\# \#}$ \\
\hline $\begin{array}{l}\text { Dispensed oral corticosteroid for asthma per } \\
\text { year } \mathrm{mg}^{+}\end{array}$ & $48(6-203)$ & $0(0-99)$ & $0.060^{\text {ตाก }}$ \\
\hline Co-medications (nonrespiratory) & $0(0-4)$ & $1(0-4)$ & $0.472^{\text {ๆก }}$ \\
\hline AQ20 score & $2(0-3.5)$ & $2(1-4)$ &  \\
\hline ACT score & $24(22-25)$ & $24(22-25)$ & $0.593^{\text {กิก }}$ \\
\hline Allergy and/or rhinitis & $14(66.7)$ & $24(68.6)$ & $>0.999^{\# \#}$ \\
\hline Asthma-related visits to healthcare ${ }^{\eta, \S}$ & $17(8-27)$ & $9(6-17)$ & $0.062^{\text {กา }}$ \\
\hline \multicolumn{4}{|c|}{ 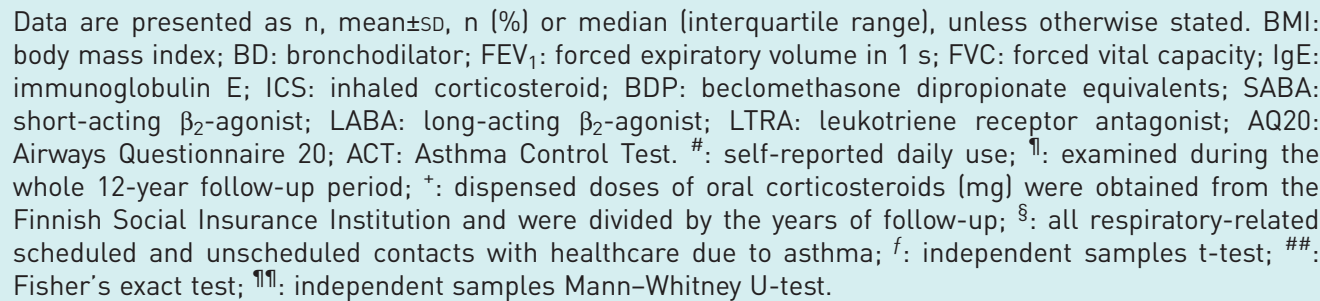 } \\
\hline
\end{tabular}

TABLE 4 Lung function change (change in pre-bronchodilator forced expiratory volume in $1 \mathrm{~s}$ $\left(\triangle \mathrm{FEV}_{1}\right)$ from maximum lung function ( $\left.\max _{0-2.5}\right)$ during the first 2.5 years after diagnosis lafter start of therapy) to 12-year follow-up visit) in patients with controlled and not-controlled asthma and different level of adherence ( $n=181)$

\begin{tabular}{|c|c|c|c|}
\hline & Good adherence $\geqslant 80 \%$ & Poor adherence $<80 \%$ & p-value \\
\hline Not-controlled asthma $n$ & & & \\
\hline$\Delta \mathrm{FEV}_{1} \mathrm{~mL} \cdot$ year $^{-1}$ & $-40(-56--20)$ & $-47(-83--32)$ & 0.024 \\
\hline$\Delta \mathrm{FEV}_{1} \%$ pred-year ${ }^{-1}$ & $-0.47(-0.98-0.25)$ & $-0.76(-1.40--0.17)$ & 0.029 \\
\hline Controlled asthma $n$ & & & \\
\hline$\Delta \mathrm{FEV}_{1} \mathrm{~mL} \cdot \mathrm{year}^{-1}$ & $-39(-59--24)$ & $-35(-67--25)$ & 0.859 \\
\hline$\Delta \mathrm{FEV}_{1} \%$ pred-year $^{-1}$ & $-0.31(-0.76-0.54)$ & $-0.34(-1.10-0.07)$ & 0.271 \\
\hline \multicolumn{4}{|c|}{$\begin{array}{l}\text { Statistical significances were evaluated by independent-samples Mann-Whitney U-test. When patients with } \\
\text { COPD were excluded from the analysis, } \Delta \mathrm{FEV}_{1} \text { was }-36(-54-18) \mathrm{mL} \cdot \mathrm{year}^{-1} \text { in patients with }>80 \% \\
\text { adherence and }-43(-78--28) \mathrm{mL} \cdot \mathrm{year}^{-1} \text { in patients with }<80 \% \text { adherence and not-controlled asthma } \\
(\mathrm{p}=0.058) \text {. }\end{array}$} \\
\hline
\end{tabular}




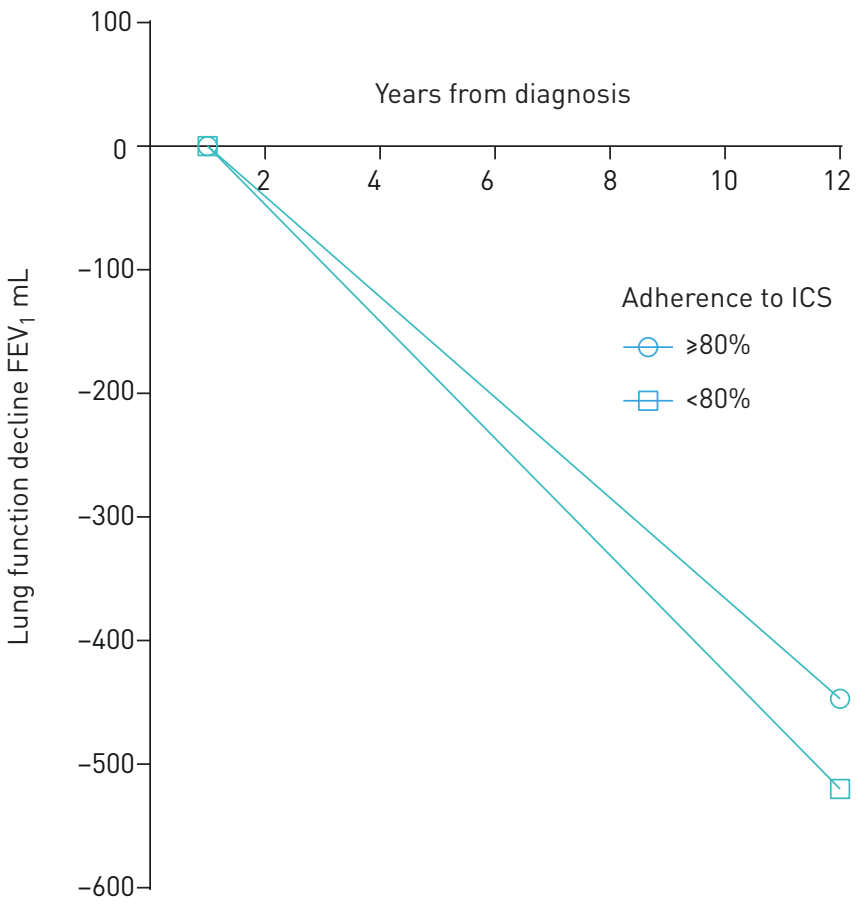

FIGURE 3 Schematic presentation of the changes in forced expiratory volume in $1 \mathrm{~s}(\mathrm{FEV})_{1}(\mathrm{~mL})$ during 12 years of follow-up in patients with not-controlled asthma and $\geqslant 80 \%$ or $<80 \%$ adherence. Model based on group medians. At the year 0 patients were steroid-naïve and inhaled corticosteroid (ICS) treatment was initiated (diagnostic visit). Origin for lung function decline is the maximal point of lung function within 2.5 years after start of treatment.

Although previous studies have suggested better ICS adherence to be associated with good disease control $[4,11-13,20]$, in this study patients with not-controlled asthma had higher 12-year adherence to long-term ICS treatment compared to patients with controlled disease. The higher proportion of adherent patients in the former group may be explained by more severe symptoms and associated need of medication [16, 21]. Conversely, patients with controlled asthma may have themselves stepped-down their ICS therapy after achieving disease control, which would appear as lower adherence rates during the follow-up. In group comparisons, $58 \%$ of the patients with not-controlled disease were current or ex-smokers and had significantly more pack-years than those with controlled asthma. This is in line with previous studies which have related smoking to worse asthma control [3, 4, 12, 32]. Furthermore, patients with not-controlled asthma were more often older, male and less often atopic compared to those with controlled disease. In addition, there was a tendency between poorer asthma control and higher BMI. In

TABLE 5 Predictors for annual decline of forced expiratory volume in $1 \mathrm{~s}\left(\mathrm{FEV}_{1}\right)(\mathrm{mL})\left(\Delta \mathrm{FEV} \mathrm{V}_{1}\right.$ from maximum lung function ( $\max _{0-2.5}$ ) during the first 2.5 years after diagnosis lafter start of therapyl to 12 -year follow-up visit) in 12-year follow-up in patients with not-controlled asthma as evaluated by multiple linear regression analysis $(n=100)$

Unstandardised B coefficient $(95 \% \mathrm{Cl})$

p-value

Age at follow-up
Female
BMI at follow-up
$\geqslant 10$ pack-years at follow-up
$\Delta \mathrm{FEV}_{1} \mathrm{~mL}$ (baseline- max $_{0-2.5}$ )
$F_{\text {eNO }}>20 \mathrm{ppb}$
Average 12 -year adherence $(<80 \%$ ) to ICS

$$
\begin{gathered}
-0.10(-0.53-0.33) \\
12.46(1.03-23.89) \\
-1.03(-2.05-0.00) \\
-7.92(-19.01-3.16) \\
-0.024(-0.04-0.01) \\
-23.48(-35.99--10.97) \\
-10.36(-20.37--0.36)
\end{gathered}
$$

In univariate analysis, unstandardised B coefficient $(95 \% \mathrm{Cl}$ ) for average 12 -year adherence $(<80 \%)$ to ICS is $-11.23(-22.15--0.32), p=0.044$. BMI: body mass index; $F_{\text {eNO }}$ : exhaled nitric oxide fraction; ICS: inhaled corticosteroid. 
patients with adult-onset asthma, phenotypes related to obesity and smoking are currently recognised, these phenotypes being at risk of poorer asthma outcomes and disease control [33-35]. Even though patients with not-controlled asthma had mean 12-year ICS adherence as high as $76 \%$, factors such as smoking and obesity may induce insensitivity to ICS and poor response to treatment [34, 36, 37]. Furthermore, in recent studies the average age of patients has been lower in comparison to our study population $[10,13,14]$ indicating that previous studies have included more patients with allergic asthma showing predominantly type 2 inflammation. Therefore, $\geqslant 80 \%$ adherence to long-term ICS treatment appears not to be effective enough to control asthma, since these patients may have had non-type 2 inflammation or untreated comorbidities.

While it seems to have been taken for granted that poor adherence is one common reason behind not-controlled asthma, previous studies in this field have usually been cross-sectional or short-term follow-ups and no long-term studies have been conducted [10-17]. These cross-sectional studies mostly included patients having asthma diagnosis but the information on age of asthma onset, diagnostic criteria or duration of asthma were often lacking [10-12, 14, 16-18]. Moreover, in previous studies asthma control has been defined as asthma symptom control assessed by the Asthma Control Test or Asthma Control Questionnaire and not including both symptoms and lung function as defined by the GINA guideline. Furthermore, adherence has been evaluated with the Medication Adherence Rating Scale or Morisky (Morisky Medication Adherence Scale) questionnaires [4, 12, 14-16, 18]. Such self-reports are widely used for assessing adherence, but may be vulnerable to the shortcomings of these memory-dependent channels. We found one 3-month clinical trial on inhaler adherence in patients with uncontrolled asthma where control was assessed according to GINA guidelines and adherence monitored with an INCA (INhaler Compliance Assessment) device, in which $27 \%$ of patients stayed refractory despite being adherent to salmeterol/fluticasone treatment and having correct inhaler technique [38]. A similar result was found in the current study where $34 \%$ of the study patients remained not controlled despite having $\geqslant 80 \%$ adherence to ICS treatment during 12-year follow-up. To our knowledge, this is the first study where asthma control is determined according to GINA guidelines in unselected patient population and adherence is confirmed longitudinally by comparing each patient's dispensed ICS medication to truly prescribed doses of ICS [8]. Furthermore, all patients with objectively confirmed diagnosis of new-onset adult asthma were included, meaning patients with comorbidities and history of smoking, for example.

When assessing lung function decline during 12-year follow-up in patients with not-controlled asthma, those with lower $(<80 \%)$ 12-year adherence had more rapid decline in $\mathrm{FEV}_{1}$ compared to patients with $\geqslant 80 \%$ adherence $(\mathrm{p}=0.024)$. This difference was not seen in patients with controlled asthma. In addition, the observed difference may be clinically meaningful since the patients with adult-onset asthma rarely remit and a level of $7 \mathrm{~mL} \cdot$ year $^{-1}$ would correspond to $140 \mathrm{~mL}$ in 20 years and $210 \mathrm{~mL}$ in 30 years. Smoking and exacerbations are also important factors associated with the decline in lung function [30]. Even though the two adherence groups with not-controlled asthma did not differ by smoking, we adjusted our analyses for smoked pack-years and found that poorer adherence $(<80 \%)$ remained a significant predictor for $\mathrm{FEV}_{1}$ decline in patients with not-controlled asthma. The finding underscores the importance of determining patients' asthma control by GINA guidelines and to assess treatment adherence. Early recognition of patients with not-controlled (partially or uncontrolled) asthma and suboptimal $(<80 \%)$ adherence should allow us to detect those patients who may be at risk of steeper lung function decline in the long term. Moreover, it may allow the opportunity to motivate them towards better adherence and thereby avoid undesirable outcomes in lung function. Conversely, this may help to identify patients whose asthma is not controlled despite high adherence to treatment. These patients may show non-type 2 inflammation, since they have higher blood neutrophil counts and current medications may not be effective enough to control their disease. These results further suggest that patients with late-onset asthma and insufficient therapeutic response need new treatment strategies and possibly other interventions such as support in smoking cessation and weight loss.

In the current study, medical records and pharmacy dispensation data were used in adherence calculations, and therefore some limitations must be addressed. The dispensed medication is not a guarantee of inhaler use, and therefore patient's adherence to treatment may be overestimated. Although patients had guidance to correct inhaler use when medication was initiated, the correct inhaler technique could not be ensured. Furthermore, asthma control was measured at follow-up visit and not regularly during the follow-up. However, the current study with an exceptionally long follow-up period is based on objectively calculated adherence data, and assessment of asthma control includes lung function according to GINA guidelines [3, 8]. It has been suggested [38] that an assessment of adherence using and electronic device could be beneficial in patients with severe asthma. According to our results such approaches could also be used in patients with not-controlled disease. Future studies should assess how guidance on adherence focused to subjects with poor adherence to ICS and not-controlled asthma affects long-term changes in lung function. 
In conclusion, we combined, for the first time, long-term adherence to ICS with asthma control determined according to GINA guideline [27]. The mean 12-year adherence to this treatment was especially high in patients with not-controlled disease. New treatment strategies combining pharmacological and nonpharmacological approaches may be needed in patients with insufficient therapeutic response. Importantly, our results showed that patients with not-controlled asthma and poor adherence $(<80 \%)$ had more rapid decline in $\mathrm{FEV}_{1}$ during 12-year follow-up compared to patients with higher adherence $(\geqslant 80 \%)$, which must be recognised to avoid negative consequences. In clinical practice, careful evaluation of patient's asthma control and adherence to treatment enhances the recognition of those patients at risk of rapid lung function decline in the long-term.

Acknowledgements: Aino Sepponen (Dept of Respiratory Medicine, Seinäjoki Central Hospital, Seinäjoki, Finland) is gratefully acknowledged for her help through all stages of this work.

Author contributions: Conception and design, H. Kankaanranta, L.E. Tuomisto, O. Niemelä and P. Ilmarinen; data analysis, I. Vähätalo and P. Ilmarinen; data collection, H. Kankaanranta, L.E. Tuomisto, O. Niemelä, P. Ilmarinen and I. Vähätalo; manuscript writing, I. Vähätalo, P. Ilmarinen and H. Kankaanranta; manuscript review and editing, I. Vähätalo, P. Ilmarinen, H. Kankaanranta, L.E. Tuomisto, O. Niemelä and L. Lehtimäki.

Support statement: This study is supported by the Tampere Tuberculosis Foundation (Tampere, Finland), the Pirkanmaa Regional Fund of the Finnish Cultural Foundation (Helsinki, Finland), the Finnish Anti-Tuberculosis Association Foundation (Helsinki, Finland), the Research Foundation of the Pulmonary Diseases (Helsinki, Finland), the Ida Montini Foundation (Kerava, Finland), Allergy Research Foundation (Helsinki, Finland), Competitive State Research Financing of the Expert Responsibility Area of Tampere University Hospital (Tampere, Finland) and the Medical Research Fund of Seinäjoki Central Hospital (Seinäjoki, Finland). None of the sponsors had any involvement in the planning, execution, drafting or write-up of this study. Funding information for this article has been deposited with the Crossref Funder Registry.

Conflict of interest: I. Vähätalo has nothing to disclose. H. Kankaanranta reports fees for lectures and consulting, costs for attending an international congress, and research grant to his institution from AstraZeneca; fees for consulting from Chiesi Pharma AB; fees for lectures and consulting, and costs for attending an international congress from Boehringer Ingelheim; fees for lectures and consulting from Novartis; fees for lectures from Mundipharma; fees for lectures and consulting, and costs for attending international congress from Orion Pharma; fees for consulting from SanofiGenzyme; and fees for lectures and consulting from GlaxoSmithKline, all outside the submitted work. L.E. Tuomisto reports costs for attending an international congress and costs for lecture from Boehringer Ingelheim, and costs for a lecture from AstraZeneca, outside the submitted work. O. Niemelä has nothing to disclose. L. Lehtimäki reports personal fees from AstraZeneca, Boehringer Ingelheim, Chiesi, Circassia, GSK, Novartis, Mundipharma, Orion Pharma, Sanofi and Teva, outside the submitted work. P. Ilmarinen reports a grant for analysis and write-up of a study, and a fee for a lecture from AstraZeneca; fees for lectures from Mundipharma and GlaxoSmithKline; and a fee for a lecture and for preparing presentation material from Novartis, all outside the submitted work.

\section{References}

1 Engelkes M, Janssens HM, de Jongste JC, et al. Medication adherence and the risk of severe asthma exacerbations: a systematic review. Eur Respir J 2015; 45: 396-407.

2 Gold LS, Smith N, Allen-Ramey FC, et al. Associations of patient outcomes with level of asthma control. Ann Allergy Asthma Immunol 2012; 109: 260-265.

3 Tuomisto LE, Ilmarinen P, Niemelä O, et al. A 12-year prognosis of adult-onset asthma: Seinäjoki Adult Asthma Study. Respir Med 2016; 117: 223-229.

4 Braido F, Brusselle G, Guastalla D, et al. Determinants and impact of suboptimal asthma control in Europe: The International Cross-Sectional and Longitudinal Assessment on Asthma Control (LIAISON) study. Respir Res 2016; 17: 51 .

5 Global Initiative for Asthma (GINA). Global Strategy for Asthma Management and Prevention. 2020. Available from: http://ginasthma.org/

6 Ilmarinen P, Tuomisto LE, Kankaanranta H. Phenotypes, risk factors and mechanisms of adult-onset asthma. Mediators Inflamm 2015; 2015: 514868.

7 Wenzel SE. Asthma phenotypes: the evolution from clinical to molecular approaches. Nat Med 2012; 18: 716-725.

8 Vähätalo I, Ilmarinen P, Tuomisto LE, et al. 12-year adherence to inhaled corticosteroids in adult-onset asthma. ERJ Open Res 2020; 6: 00324-2019.

9 Krishnan JA, Bender BG, Wamboldt FS, et al. Adherence to inhaled corticosteroids: an ancillary study of the Childhood Asthma Management Program clinical trial. J Allergy Clin Immunol 2012; 129: 112-118.

10 Kosse RC, Koster ES, Kaptein AA, et al. Asthma control and quality of life in adolescents: the role of illness perceptions, medication beliefs, and adherence. J Asthma 2020; 57: 1145-1154.

11 Allegra L, Cremonesi G, Girbino G, et al. Real-life prospective study on asthma control in Italy: cross-sectional phase results. Respir Med 2012; 106: 205-214.

12 Clatworthy J, Price D, Ryan D, et al. The value of self-report assessment of adherence, rhinitis and smoking in relation to asthma control. Prim Care Respir J 2009; 18: 300-305.

13 Dima AL, van Ganse E, Stadler G, et al. Does adherence to inhaled corticosteroids predict asthma-related outcomes over time? A cohort study. Eur Respir J 2019; 54: 1900901.

14 Price D, Harrow B, Small M, et al. Establishing the relationship of inhaler satisfaction, treatment adherence, and patient outcomes: a prospective, real-world, cross-sectional survey of US adult asthma patients and physicians. World Allergy Organ J 2015; 8: 26.

15 Roche N, Plaza V, Backer V, et al. Asthma control and COPD symptom burden in patients using fixed-dose combination inhalers (SPRINT study). NPJ Prim Care Respir Med 2020; 30: 1. 
Smits D, Brigis G, Pavare J, et al. Factors related to good asthma control using different medical adherence scales in Latvian asthma patients: an observational study. NPJ Prim Care Respir Med 2017; 27: 39.

17 Munoz-Cano R, Torrego A, Bartra J, et al. Follow-up of patients with uncontrolled asthma: clinical features of asthma patients according to the level of control achieved (the COAS study). Eur Respir J 2017; 49: 1501885.

18 Chiu KC, Boonsawat W, Cho SH, et al. Patients' beliefs and behaviors related to treatment adherence in patients with asthma requiring maintenance treatment in Asia. J Asthma 2014; 51: 652-659.

19 Ilmarinen P, Tuomisto LE, Niemelä O, et al. Prevalence of patients eligible for anti-IL-5 treatment in a cohort of adult-onset asthma. J Allergy Clin Immunol Pract 2019; 7: 165-174.

20 Klok T, Kaptein AA, Duiverman EJ, et al. It's the adherence, stupid (that determines asthma control in preschool children)!. Eur Respir J 2014; 43: 783-791.

21 Papi A, Ryan D, Soriano JB, et al. Relationship of inhaled corticosteroid adherence to asthma exacerbations in patients with moderate-to-severe asthma. J Allergy Clin Immunol Pract 2018; 6: 1989-1998.

22 Kandane-Rathnayake RK, Matheson MC, Simpson JA, et al. Adherence to asthma management guidelines by middle-aged adults with current asthma. Thorax 2009; 64: 1025-1031.

23 Murphy AC, Proeschal A, Brightling CE, et al. The relationship between clinical outcomes and medication adherence in difficult-to-control asthma. Thorax 2012; 67: 751-753.

24 Vähätalo I, Ilmarinen P, Tuomisto LE, et al. Inhaled corticosteroids and asthma control in adult-onset asthma: 12-year follow-up study. Respir Med 2018; 137: 70-76.

25 Kankaanranta H, Ilmarinen P, Kankaanranta T, et al. Seinäjoki Adult Asthma Study (SAAS): a protocol for a 12-year real-life follow-up study of new-onset asthma diagnosed at adult age and treated in primary and specialised care. NPJ Prim Care Respir Med 2015; 25: 15042.

26 Haahtela T, Klaukka T, Koskela K, et al. Asthma programme in Finland: a community problem needs community solutions. Thorax 2001; 56: 806-814.

27 Global Initiative for Asthma (GINA). Global Strategy for Asthma Management and Prevention. 2010. Available from: http://ginasthma.org/

28 Bijlsma MJ, Janssen F, Hak E. Estimating time-varying drug adherence using electronic records: extending the proportion of days covered (PDC) method. Pharmacoepidemiol Drug Saf 2016; 25: 325-332.

29 van Boven JFM, Koponen M, Lalic S, et al. Trajectory analyses of adherence patterns in a real-life moderate to severe asthma population. J Allergy Clin Immunol Pract 2020; 8: 1961-1969.

30 Tommola M, Ilmarinen P, Tuomisto LE, et al. The effect of smoking on lung function: a clinical study of adult-onset asthma. Eur Respir J 2016; 48: 1298-1306.

31 Dreborg S, Frew AJ. Position paper: allergen standardization and skin tests. Allergy 1993; 48: 49-54.

32 Chaudhuri R, McSharry C, McCoard A, et al. Role of symptoms and lung function in determining asthma control in smokers with asthma. Allergy 2008; 63: 132-135.

33 Ilmarinen P, Tuomisto LE, Niemelä O, et al. Comorbidities and elevated IL-6 associate with negative outcome in adult-onset asthma. Eur Respir J 2016; 48: 1052-1062.

34 Ilmarinen $\mathrm{P}$, Tuomisto LE, Niemelä O, et al. Cluster analysis on longitudinal data of patients with adult-onset asthma. J Allergy Clin Immunol Pract 2017; 5: 967-978.

35 Lefaudeux D, De Meulder B, Loza MJ, et al. U-BIOPRED clinical adult asthma clusters linked to a subset of sputum omics. J Allergy Clin Immunol 2017; 139: 1797-1807.

36 Lazarus SC, Chinchilli VM, Rollings NJ, et al. Smoking affects response to inhaled corticosteroids or leukotriene receptor antagonists in asthma. Am J Respir Crit Care Med 2007; 175: 783-790.

37 Tomlinson JE, McMahon AD, Chaudhuri R, et al. Efficacy of low and high dose inhaled corticosteroid in smokers versus non-smokers with mild asthma. Thorax 2005; 60: 282-287.

38 Sulaiman I, Greene G, MacHale E, et al. A randomised clinical trial of feedback on inhaler adherence and technique in patients with severe uncontrolled asthma. Eur Respir J 2018; 51: 1701126. 